\title{
Study on dynamic sorption characteristics of modified biochars for ammonium in biogas slurry
}

\author{
Jingtao Ding ${ }^{1,2}$, Yujun Shen ${ }^{1,2}$, Yanru Ma ${ }^{1,2,3}$, Haibo Meng ${ }^{1,2^{*}}$, Hongsheng Cheng ${ }^{1,2}$, \\ Xi Zhang ${ }^{1,2}$, Jian Wang ${ }^{1,2}$, Pengyue Zhang ${ }^{1,2}$ \\ (1. Institute of Energy and Environmental Protection, Academy of Agricultural Planning \& Engineering, \\ Ministry of Agriculture and Rural Affairs, Beijing 100125, China; \\ 2. Key Laboratory of Technologies and Models for Cyclic Utilization from Agricultural Resources, \\ Ministry of Agriculture and Rural Affairs, Beijing 100125, China; \\ 3. College of Engineering, Huazhong Agricultural University, Wuhan 430070, China)
}

\begin{abstract}
The objective of this study was to investigate the relationship between ammonium $\left(\mathrm{NH}_{4}{ }^{+} \mathrm{N}\right)$ dynamic sorption capacity and physicochemical properties of modified biochars. Biochars, producing from three species of agricultural wastes of cornstalk (A), corncob (B) and sawdust (C) at $550^{\circ} \mathrm{C}, 600^{\circ} \mathrm{C}$ and $650^{\circ} \mathrm{C}$, were modified by four methods of $\mathrm{NaOH}$ plus microwave $(\mathrm{NaM}), \mathrm{KOH}(\mathrm{K}), \mathrm{FeCl}_{3}(\mathrm{Fe})$ and $\mathrm{HNO}_{3}(\mathrm{H})$. The static and dynamic adsorption experiments were conducted to investigate sorption characteristics of modified biochars on $\mathrm{NH}_{4}{ }^{+}-\mathrm{N}$ in slurry of piggery manure anaerobic digestate. Four modified biochars with better $\mathrm{NH}_{4}{ }^{+}-\mathrm{N}$ adsorption rates were selected through static kinetics adsorption tests, which showed that chemical reactions might have occurred during the $\mathrm{NH}_{4}{ }^{+}-\mathrm{N}$ sorption process and the maximum $\mathrm{NH}_{4}{ }^{+}-\mathrm{N}$ removal rates of B-550-Fe, A-550-NaM, A-550-K and C-600-NaM were $66.64 \%, 57.50 \%, 52.39 \%$ and $45.20 \%$, respectively. The dynamic adsorption column experiment was conducted in a three-stage adsorption column packed with the selected three modified biochars. $\mathrm{NH}_{4}{ }^{+} \mathrm{N}$ dynamic adsorption depended on the slurry inflow flow rate, the type of biochar and the depth of packed biochar. The optimal adsorption process was elected by the method of orthogonal experiment. The data showed that using deeper packed biochar and applying lower flow rates could be a better strategy to increase $\mathrm{NH}_{4}{ }^{+}-\mathrm{N}$ adsorption. The maximum $\mathrm{NH}_{4}^{+}-\mathrm{N}$ removal rate in the slurry could reach $85.60 \%$ in the three-stage adsorption process. It concluded that $\mathrm{NH}_{4}^{+}-\mathrm{N}$ adsorption in three-stage adsorption process could be an effective method to recover nitrogen from piggery manure anaerobic digestate.
\end{abstract}

Keywords: modified biochar, biogas slurry, ammonium adsorption, sorption characteristics DOI: $10.25165 /$ j.ijabe.20201301.4697

Citation: Ding J T, Shen Y J, Ma Y R, Meng H B, Cheng H S, Zhang X, et al. Study on dynamic sorption characteristics of modified biochars for ammonium in biogas slurry. Int J Agric \& Biol Eng, 2020; 13(1): 234-240.

\section{Introduction}

Anaerobic digestion technology is the worldwide applied technology for treating livestock manure ${ }^{[1]}$. Anaerobic digestion projects also produce a large amount of digestates, which are renowned for containing high nutrients mainly nitrogen and phosphorus compounds that often pollute the environment ${ }^{[2-4]}$. In China, the chemical oxygen demand (COD), total nitrogen (TN) and total phosphorus (TP) from the livestock breeding industry

Received date: 2018-10-07 Accepted date: 2019-01-10

Biographies: Jingtao Ding, PhD, Senior Engineer, research interests: cyclic utilization from agricultural resources, Email: dingjingtao@caaepd.org.cn; Yujun Shen, $\mathrm{PhD}$, Senior Engineer, research interests: cyclic utilization from agricultural resources, Email: shenyujun@caaepd.org.cn; Yanru Ma, PhD, research interests: cyclic utilization from agricultural resources, Email: mayanru168@163.com; Hongsheng Cheng, PhD, Senior Engineer, research interests: cyclic utilization from agricultural resources, Email: chenghongsheng@caaepd.org.cn; Xi Zhang, PhD, Senior Engineer, research interests: fertilizer utilization of agricultural wastes, Email: zhangxi@, caaepd.org.cn; Jian Wang, PhD, Engineer, research interests: cyclic utilization from agricultural resources, Email: wangjian@caaepd.org.cn; Pengyue Zhang, MA Eng, Assistant Engineer, research interests: cyclic utilization from agricultural resources, Email: yue.zp@foxmail.com.

*Corresponding author: Haibo Meng, $\mathrm{PhD}$, Professor, research interests: biomass utilization. No.41, Maizidian Street, Chaoyang District, Beijing 100125, China. Tel: +86-10-59197288, Email: menghaibo@caaepd.org.cn. accounted for $96 \%, 38 \%$ and $56 \%$ of the total pollutants from agricultural sources respectively and were 2.3 times that of industrial sources, according to the China pollution source census carried out in 2010. The biogas projects produced about $1.12 \mathrm{t}$ of slurry every year. Nowadays, Chinese biogas projects produce about $1.12 \mathrm{t}$ of anaerobic digestate slurry every year ${ }^{[5]}$, in which the content of ammonia nitrogen $\left(\mathrm{NH}_{4}{ }^{+}-\mathrm{N}\right)$ is as high as $80 \%$ of $\mathrm{TN}^{[6]}$. The slurry pollution puts a lot of pressure on the environmental protection.

To reduce the environmental pollutions from biogas slurry, several methods ranging from biological, physical, chemical or a combination of these have been explored. Ammonium recovery from slurry and reuse has been one of the effective methods to treat and recycle utilize anaerobic digestate slurry ${ }^{[7-9]}$. In recently years, the potential use of biochar as a better adsorbing material has been proposed as an alternative treatment in sewage treatment and nutrient recovery ${ }^{[10-13]}$. Biochar is described as porous solid carbonaceous material producible through pyrolysis of a wide range of biomass in anoxic conditions at temperatures ranges of $300^{\circ} \mathrm{C}-1500^{\circ} \mathrm{C}^{[14]}$. Biochars have long-term potential for soil water retention ${ }^{[15-18]}$, adsorption and fixation of nutrient elements ${ }^{[19]}$, due to its favorable characteristics such as high surface area, high porosity, cation exchange capacity and $\mathrm{pH}$ buffering ability. To enhance adsorption capacities of biochar, physical and chemical modification on biochar have also emerged as a hot field of 
research directions. After been modified, the chemical property of biochars are more stable and are more conducive for adsorption of nutrients and different organic pollutants from domestic, agricultural and industrial waste waters ${ }^{[20-24]}$. Modified carbon with adsorbed nutrient can be used as soil amendment to enhance soil fertility and crop yield due to the adsorbed nutrients are slowly released for use by plants.

At present, the capacity of biochar to take up $\mathrm{NH}_{4}{ }^{+}-\mathrm{N}$ from sewage is well recognized by the ways of static adsorption experiments in laboratory studies ${ }^{[20,21]}$. However, from our literature survey, the application of biochar to treat piggery manure anaerobic digestate slurry for nutrient recovery has not been fully researched. Moreover, few studies have been conducted in describing ammonium adsorption dynamic behavior for biogas slurry based on modified biochar, which could provide data that could be easily scaled up to suit real-field engineering perspective. Therefore, this study investigated the performance of ammonium adsorption removal from piggery manure anaerobic digestate slurry in a three-stage adsorption column packed with the selected three modified biochars. Through dynamic adsorption test, the effects of operational parameters (packed height, modified biochar mass, and slurry influent rate) on ammonium adsorption capacity, breakthrough time, and saturation time have been evaluated. This study could give a viable technology for recovery of ammonium from anaerobic digestate on a small-to-medium scale, thereby reducing treatment costs and overcoming inefficiencies of conventional methods.

\section{Materials and methods}

\subsection{Modified biochar production}

The raw materials to produce biochars were cornstalk, corncob and sawdust, which were taken from rural areas in Daxing district, Beijing, China. The raw materials were firstly crushed to pieces $(5-10 \mathrm{~cm})$, followed by cleaning and sieving before being modified. The pretreated biomass was then dried at $105^{\circ} \mathrm{C}$, and then were transformed to biochars under $\mathrm{N}_{2}$ gas pyrolysis at $550^{\circ} \mathrm{C}, 600^{\circ} \mathrm{C}$ and $650^{\circ} \mathrm{C}$ using tube furnace (OTF-1200X). After cooling down, the 9 kinds of biochars were smashed to 60 mesh sieve for the following modification. The modified solutions we choose were $\mathrm{NaOH}(2 \mathrm{~mol} / \mathrm{L}), \mathrm{KOH}(2 \mathrm{~mol} / \mathrm{L}), \mathrm{HNO}_{3}(2 \mathrm{~mol} / \mathrm{L})$ and $\mathrm{FeCl}_{3}$ $(1.5 \mathrm{~mol} / \mathrm{L})$. Each kind of quantitative biochar $(50 \mathrm{~g})$ was added into $200 \mathrm{~mL}$ modified solution at $70^{\circ} \mathrm{C}$ for $2 \mathrm{~h}$, and they were placed in the oscillator (at $35^{\circ} \mathrm{C}$ and $120 \mathrm{r} / \mathrm{min}$ ) for $24 \mathrm{~h}$. Then the biochars were washed with deionized water until $\mathrm{pH}$ of the washings was neutral. To get the modified biochar of $\mathrm{NaOH}$ plus microwave, the biochar modified with $\mathrm{NaOH}$ was further modified in a microwave equipment (Microwave dissolver, WXJ-III) at $800 \mathrm{~W}$ power. All the modified biochars were dried at $70^{\circ} \mathrm{C}$ for the following experiment.

\subsection{Biochar characteristics analysis}

Specific surface area, pore size distribution and porosity of biochar were characterized by mercury intrusion spectrometer (AutoPore IV9520, made in United States of America). Functional group and surface structure analysis were characterized by Fourier transform infrared spectroscopy (VERTEX 70v, made in Germany) and scanning electron microscopy (FEI Quanta FEG 650, made in United States of America), respectively.

\subsection{Static adsorption experiment}

Slurry of piggery manure anaerobic digestate was sampled in Donghuashan biogas project, Shunyi district, Beijing, China. $\mathrm{NH}_{4}{ }^{+}-\mathrm{N}$ concentration and $\mathrm{pH}$ of the slurry were $1856.5 \pm$
$142.2 \mathrm{mg} / \mathrm{L}$ and $8.1 \pm 0.2$, respectively. In the static adsorption experiment, $7.5 \mathrm{~g}$ modified biochar was mixed with $30 \mathrm{~mL}$ biogas slurry in the $50 \mathrm{~mL}$ centrifuge tube. The centrifuge tube was then put into the Oscillator with temperature of $25^{\circ} \mathrm{C}$ and rate of $150 \mathrm{r} / \mathrm{min}$. Slurry samples were taken at the time of $1,2,3,5,15$, $60,120,240,480$ and $720 \mathrm{~min}$ after the mixture. The slurry samples were filtered using a filter membrane with $0.45 \mu \mathrm{m}$. $\mathrm{NH}_{4}{ }^{+}-\mathrm{N}$ concentration of the filtrate was determined by UV spectrophotometer (i7, made in China).

\subsection{Dynamic adsorption column experiment}

The dynamic adsorption column experiment was conducted in three-stage acrylic plastic columns with an internal diameter of $70 \mathrm{~mm}$ and height of $1000 \mathrm{~mm}$ (Figure 1). The columns were separately packed with the three biochar types. To study the parameters of dynamic adsorption, an orthogonal experiment of 3 factors with 3 levels was conducted. The injected biogas slurry flow rate was set at $3 \mathrm{~L} / \mathrm{h}\left(\mathrm{A}_{1}\right), 5 \mathrm{~L} / \mathrm{h}\left(\mathrm{A}_{2}\right)$ and $7 \mathrm{~L} / \mathrm{h}\left(\mathrm{A}_{3}\right)$. Types of packed modified biochar were B-550-Fe $\left(\mathrm{C}_{1}\right)$, A-550-K $\left(\mathrm{C}_{2}\right)$ and A-500-NaM $\left(\mathrm{C}_{3}\right)$. Packing height of modified biochar were set at $30 \mathrm{~cm}\left(\mathrm{~B}_{1}\right), 50 \mathrm{~cm}\left(\mathrm{~B}_{2}\right)$ and $70 \mathrm{~cm}\left(\mathrm{~B}_{3}\right)$. Through the analysis of orthogonal experiment results, the dynamic adsorption capacity of $\mathrm{NH}_{4}{ }^{+} \mathrm{N}$ in biogas slurry and the operation time of the dynamic adsorption system were studied to obtain the optimum process of dynamic adsorption for $\mathrm{NH}_{4}{ }^{+}-\mathrm{N}$ in biogas slurry.

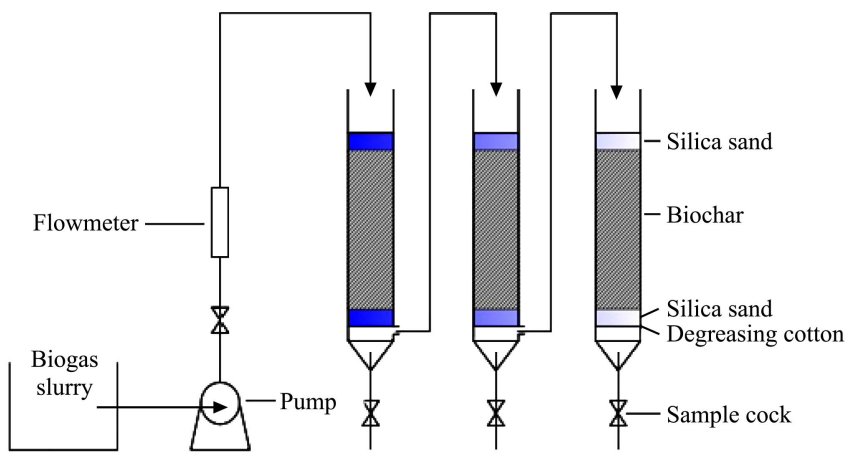

Figure 1 Dynamic adsorption experimental device

\subsection{Data analysis}

In order to investigate the mechanisms involved during the sorption processes, the kinetics of $\mathrm{NH}_{4}{ }^{+} \mathrm{N}$ sorption on biochars were described using a pseudo first order kinetic model and a pseudo second order kinetic model presented as follows:

$$
\begin{gathered}
q_{t}=q_{e}\left(1-e^{-k_{1} t}\right) \\
q_{t}=k_{2} q_{e}^{2} t /\left(1+k_{2} q_{e} t\right)
\end{gathered}
$$

where, $k_{1}$ is the rate constant of the pseudo first order sorption, $\min ^{-1} ; k_{2}$ is the pseudo second order rate constant, $\mathrm{g} / \mathrm{mg} \cdot \mathrm{min} ; q_{t}$ is the sorption amount of $\mathrm{NH}_{4}{ }^{+}-\mathrm{N}$ onto biochars at time $t, \mathrm{mg} / \mathrm{g}$; and $q_{e}$ is the mass of sorbate sorbed at equilibrium.

The results of dynamic adsorption column experiments were the average of three replications. The amount of $\mathrm{NH}_{4}{ }^{+} \mathrm{N}$ sorbed and its removal rate from the solution were calculated based on their concentration differences in the initial and the breakthrough point. The sorption amount $Q(\mathrm{mg} / \mathrm{g})$ onto biochars and its removal rate $R(\%)$ was obtained as follows:

$$
\begin{gathered}
Q=\left(C_{0}-C_{e}\right) V / W_{A} \\
R=\left(C_{0}-C_{e}\right) / C_{0} \times 100 \%
\end{gathered}
$$

where, $C_{0}$ and $C_{e}$ are the $\mathrm{NH}_{4}{ }^{+}-\mathrm{N}$ concentration $(\mathrm{mg} / \mathrm{L})$ of biogas slurry at initial and the time of breakthrough point, respectively; $W_{A}$ is the quality of biochar used in adsorption column, $\mathrm{g}$; $V$ is the volume of biogas slurry throughout the column at breakthrough point, $\mathrm{L}$. 


\section{Results and discussion}

\subsection{Selecting modified biochars with high $\mathrm{NH}_{4}{ }^{+}-\mathrm{N}$ adsorption capacity}

Biochars with larger specific surface area may have a larger adsorption capacity. In this study, specific surface area of the modified biochars, Varying in a wide range from $15.0 \mathrm{~m}^{2} / \mathrm{g}$ to $169.83 \mathrm{~m}^{2} / \mathrm{g}$ (Figure 2), increased apparently as compared to the unmodified biochars. The corncob biochars had larger specific surface area than the other two kinds of biochars. Obviously, the biochar modified by $\mathrm{NaOH}$ plus microwave $(\mathrm{NaM})$ and $\mathrm{FeCl}_{3}(\mathrm{Fe})$ had larger specific surface area than the other two modified methods of $\mathrm{KOH}(\mathrm{K})$ and $\mathrm{HNO}_{3}(\mathrm{H})$. B-600-Fe had a larger surface area $\left(169.83 \mathrm{~m}^{2} / \mathrm{g}\right)$ than the other biochars. For the corn straw biochars, the modified biochars with the higher specific surface area were A-650-NAM $\left(66.30 \mathrm{~m}^{2} / \mathrm{g}\right)$, A-650-Fe $\left(60.81 \mathrm{~m}^{2} / \mathrm{g}\right)$ and A-550-NaM $\left(58.66 \mathrm{~m}^{2} / \mathrm{g}\right)$, respectively. For the corncob biochars, the modified biochars with the higher specific surface area were B-650-Fe $\left(169.828 \mathrm{~m}^{2} / \mathrm{g}\right)$, and B-600-Fe $\left(168.62 \mathrm{~m}^{2} / \mathrm{g}\right)$ and B-550-Fe $\left(163.76 \mathrm{~m}^{2} / \mathrm{g}\right)$, respectively. For the sawdust biochars, the modified biochars with the higher specific surface area were C-550-Fe $\left(45.47 \mathrm{~m}^{2} / \mathrm{g}\right), \mathrm{C}-600-\mathrm{NaM}\left(43.43 \mathrm{~m}^{2} / \mathrm{g}\right)$ and C-550-NaM $\left(38.22 \mathrm{~m}^{2} / \mathrm{g}\right)$, respectively.

The specific surface area of biochar was an important factor affecting the adsorption capacity of $\mathrm{NH}_{4}{ }^{+}-\mathrm{N}$, but it's not the only one. Additionally, the physico-chemical properties of biochar such as yield, ash, specific surface area, elemental composition, $\mathrm{pH}$, surface functional groups could influence adsorption mechanisms of biochar on $\mathrm{NH}_{4}^{+}-\mathrm{N}^{[21]}$. To quickly screen out biochars with good adsorption performance on $\mathrm{NH}_{4}{ }^{+}-\mathrm{N}$, an extra experiment was conducted in pure $\mathrm{NH}_{4} \mathrm{Cl}$ solution. The results showed that the modified biochars with $\mathrm{NH}_{4}^{+}-\mathrm{N}$ adsorption capacity were A-550-NaM $(8.51 \mathrm{mg} / \mathrm{g}), \mathrm{B}-550-\mathrm{Fe}(8.09 \mathrm{mg} / \mathrm{g})$, A-550-K (7.58 mg/g) and C-600-NaM (7.60 mg/g) (Figure 3). The pore diameter of the four modified samples was below $2 \mathrm{~nm}$, while the pore diameter of unmodified biochars was ranged from $2 \mathrm{~nm}$ to $50 \mathrm{~nm}$. Take A-550-NaM for an example, the surface porosity increased and the surface pore channels expanded compare with A-550-N, facilitating $\mathrm{NH}_{4}{ }^{+} \mathrm{N}$ to enter the active site (Figure 4).

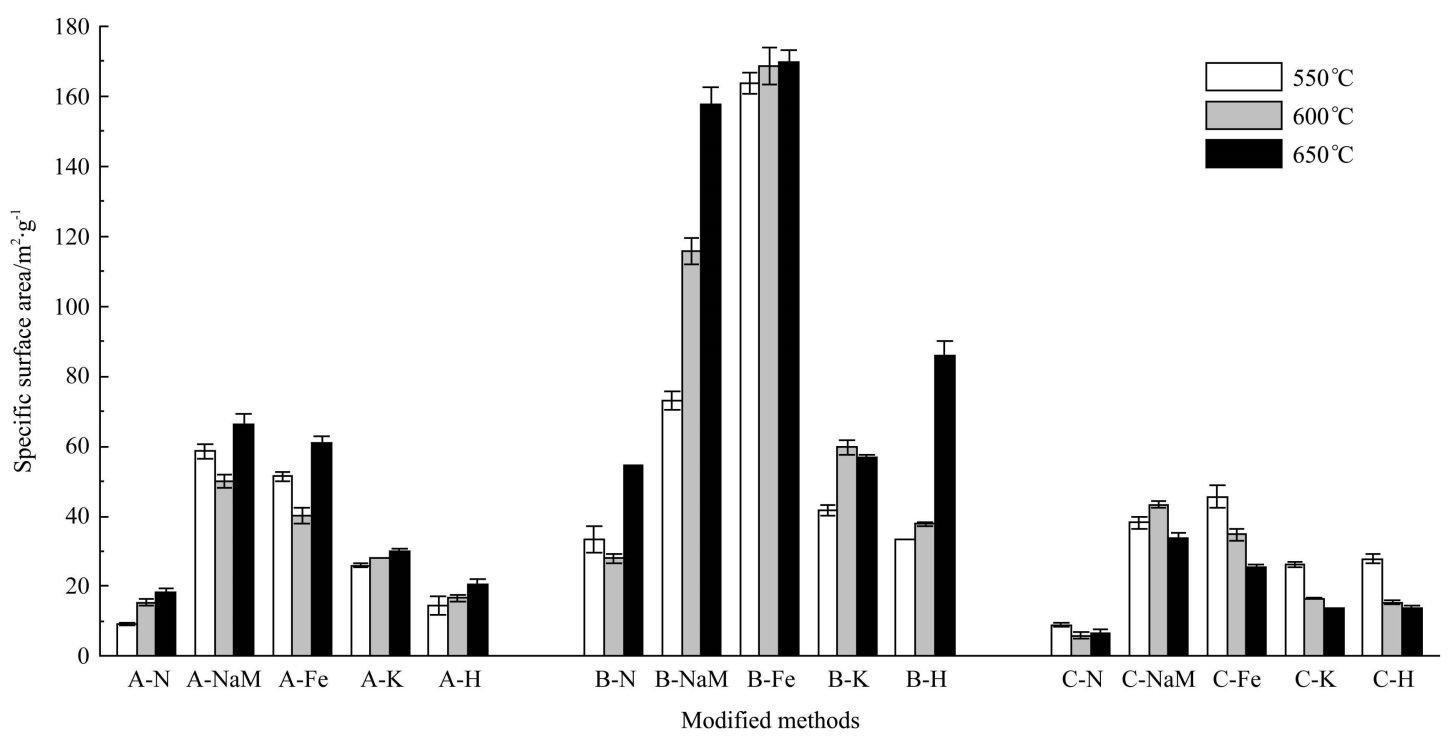

Figure 2 Specific surface area of various studied biochars

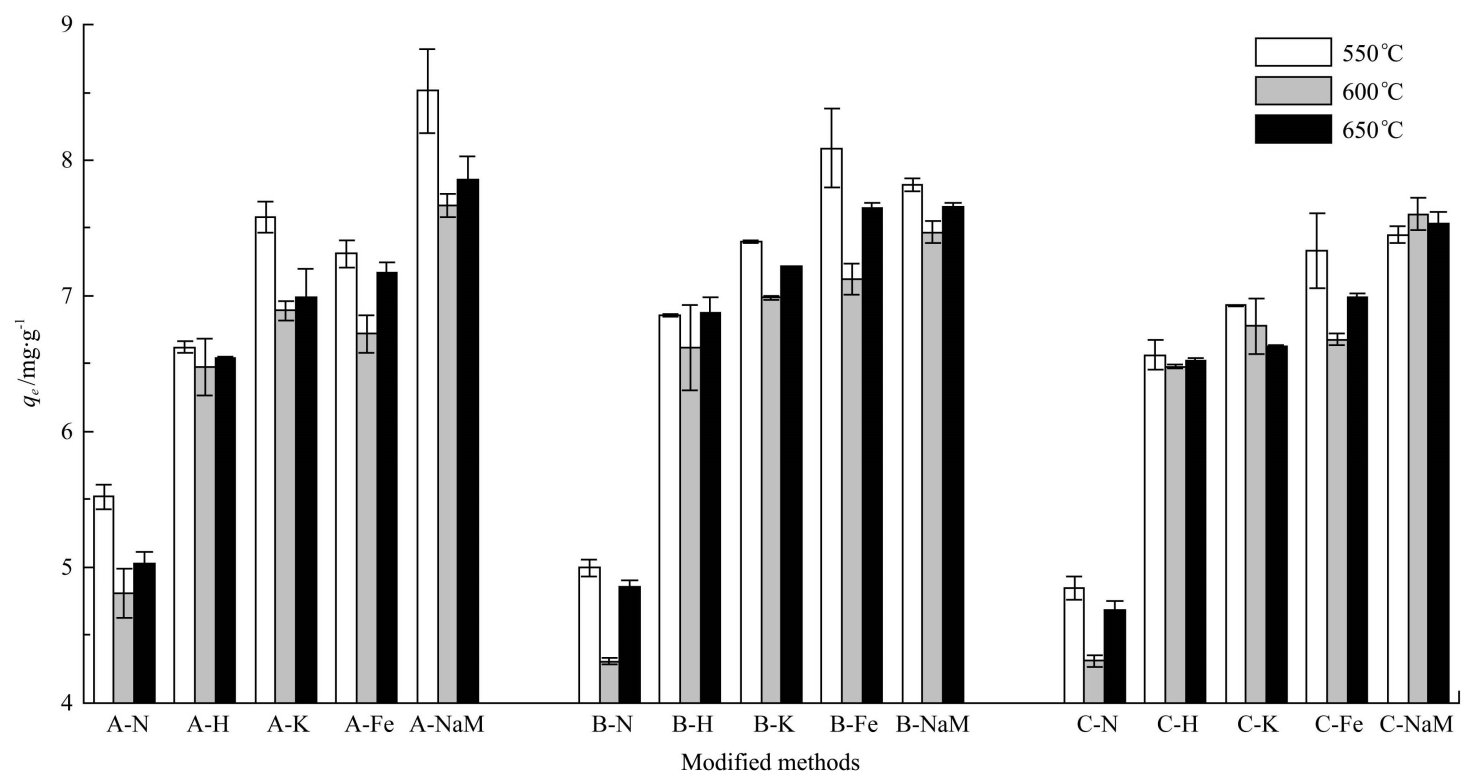

Figure $3 \mathrm{NH}_{4}{ }^{+}-\mathrm{N}$ adsorption capacities of all studied biochars 


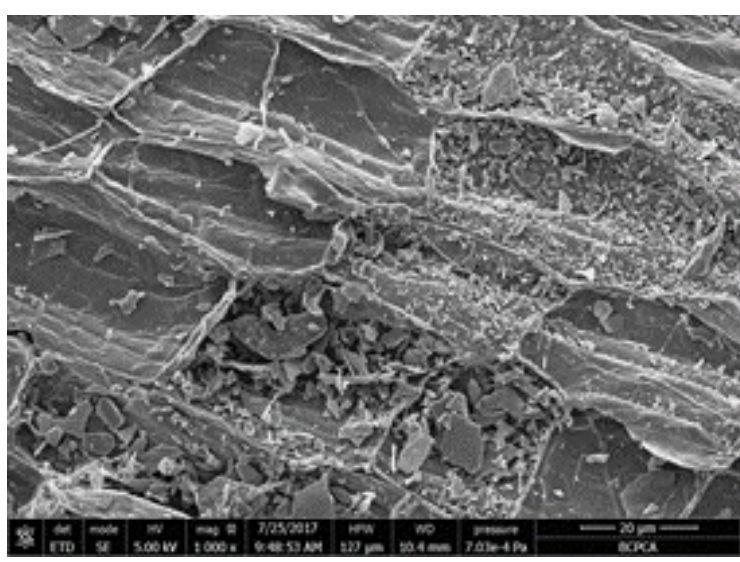

A-550-N

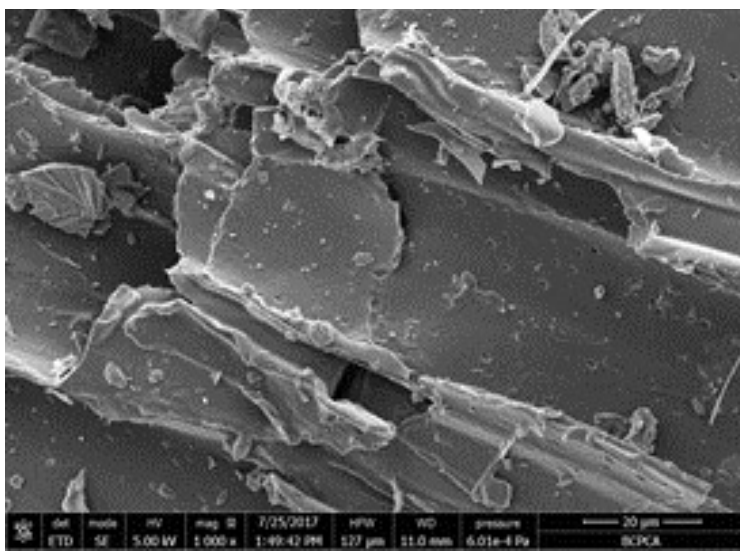

A-550-NaM

Figure 4 SEM of A-550-NaM biochar

A-550-NaM, B-550-Fe and A-550-K had a similar pattern on the FTIR spectra, which may be attributed to the uniform pyrolysis temperature used ${ }^{[25]}$ (Figure 5). According to standards from reference book and previous studies ${ }^{[26]}$, the band at $1579 \mathrm{~cm}^{-1}$ represents carboxyl group (-COOH). The bands at 2916 and $2852 \mathrm{~cm}^{-1}$ are assigned to methylene group $\left(-\mathrm{CH}_{2}\right)$. There was an obvious valley in the range of $3362 \mathrm{~cm}^{-1}$, indicating that the surface of biochars was mainly hydroxyl (-OH). By on, Functional groups of $-\mathrm{OH}$ and $-\mathrm{COOH}$ were on the surface of A-550-NaM, $\mathrm{A}-550-\mathrm{K}$ and $\mathrm{B}-550-\mathrm{Fe}$. The two functional groups could enhance the electrostatic adsorption on $\mathrm{NH}_{4}{ }^{+}-\mathrm{N}$. At the same time, there was a peak in the range of $2925 \mathrm{~cm}^{-1}$, where $-\mathrm{CH}_{2}$ increased. The peak values around $1000 \mathrm{~cm}^{-1}$ represents the stretching vibration of lactones groups, indicating the enhanced aromaticity to the benefit of adsorption capacities. B-550-Fe surface was loaded with $\mathrm{Fe}^{3+}$, which could active the surface functional groups of biochar. The enhanced hydrophilicity of biochar could improve the cation exchange performance. Meanwhile, after oxidation of $\mathrm{NaOH}$ and $\mathrm{KOH}$, more oxygen-containing functional groups were formed on the surface of biochar.

\subsection{Static kinetic sorption}

The selected four modified biochars of A-550-NaM, B-550-Fe, A-550-K and C-600-NaM were used to study their static adsorption capacities of $\mathrm{NH}_{4}{ }^{+}-\mathrm{N}$ in biogas slurry. Similar to typical kinetic process, $\mathrm{NH}_{4}{ }^{+}-\mathrm{N}$ sorption on the four modified biochars was fast in the initial $30 \mathrm{~min}$ and reached equilibrium in $150 \mathrm{~min}$ (Figure 6). In order to investigate reaction mechanisms, the sorption data were

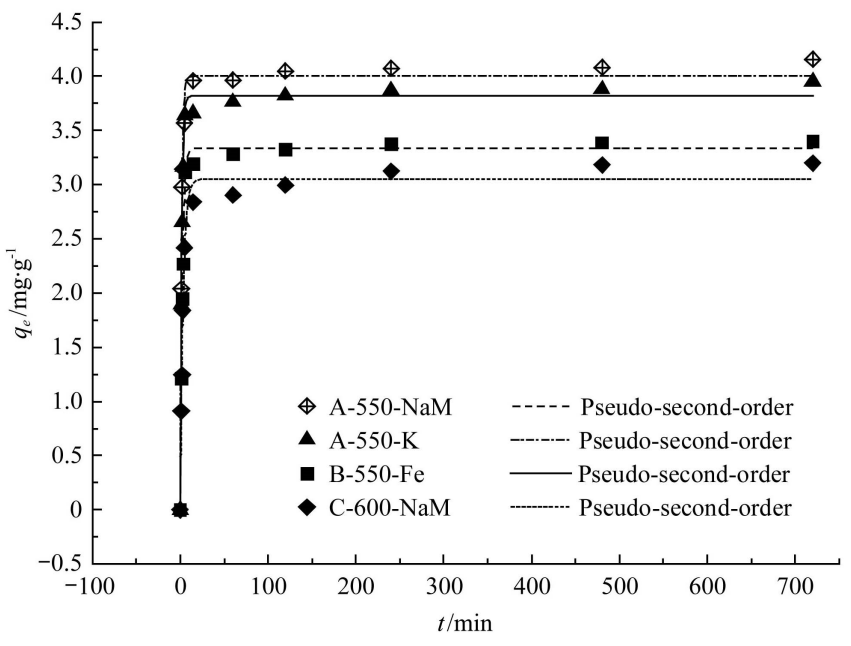

fitted with kinetic models, including the pseudo first order, pseudo second order and intra-particle diffusion model (Table 3). For the other three modified biochars, the correlation coefficient of Pseudo-second-order kinetic equation were higher than that of Pseudo-first-order, implying that chemical reactions, e.g., exchange of cations, complexation and precipitation, might have occurred during the $\mathrm{NH}_{4}{ }^{+}-\mathrm{N}$ sorption process ${ }^{[25,27]}$. The maximum $\mathrm{NH}_{4}{ }^{+}-\mathrm{N}$ removal rates of B-550-Fe, A-550-NaM, A-550-K and C-600-NaM were $66.64 \%, 57.50 \%, 52.39 \%$ and $45.20 \%$, respectively.

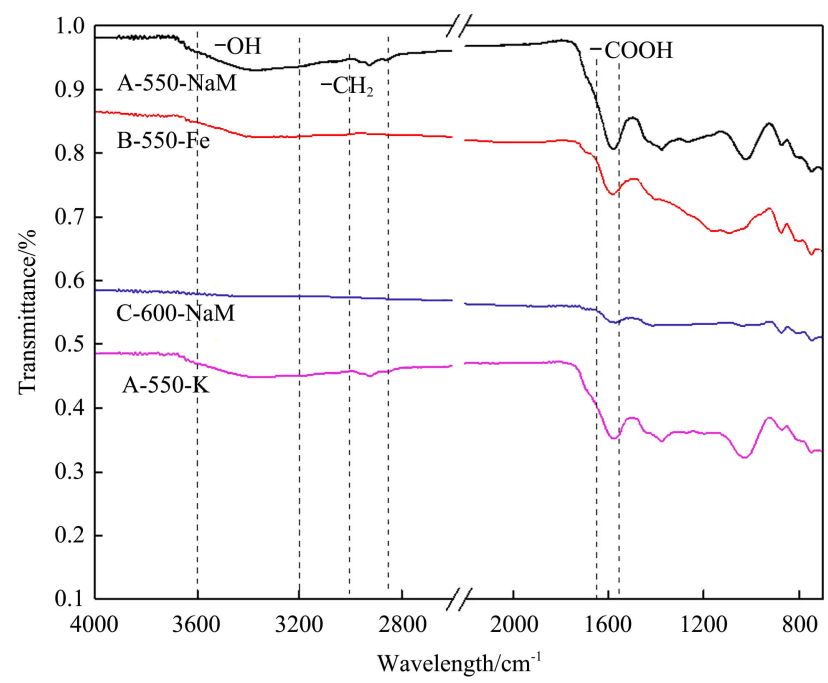

Figure 5 FTIR of four modified biochars

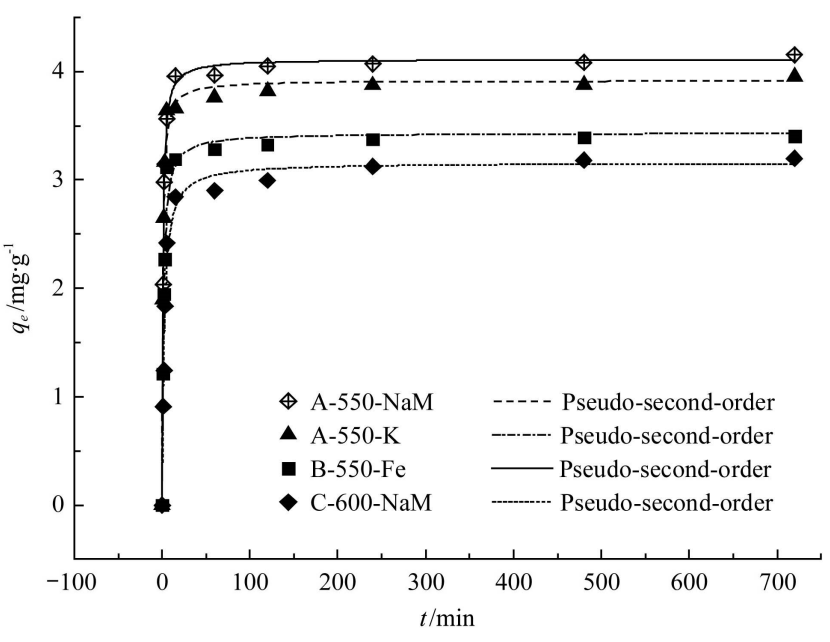

Figure 6 Four modified biochars adsorption kinetic curves of $\mathrm{NH}_{4}{ }^{+}-\mathrm{N}$ in biogas slurry 
Table 3 Adsorption kinetic parameters of $\mathrm{NH}_{4}{ }^{+}-\mathrm{N}$ in biogas slurry

\begin{tabular}{|c|c|c|c|c|c|c|c|c|}
\hline \multirow{2}{*}{ Sample } & \multicolumn{4}{|c|}{ Pseudo-first-order } & \multicolumn{4}{|c|}{ Pseudo-second-order } \\
\hline & $q_{e} / \mathrm{mg} \cdot \mathrm{g}^{-1}$ & $k_{1}$ & $R_{1}^{2}$ & $x_{1}^{2}$ & $q_{e} / \mathrm{mg} \cdot \mathrm{g}^{-1}$ & $k_{2}$ & $R_{2}{ }^{2}$ & $x_{2}^{2}$ \\
\hline $\mathrm{B}-550-\mathrm{Fe}$ & 4.000 & 0.624 & 0.985 & 0.024 & 4.114 & 0.273 & 0.995 & 0.007 \\
\hline A-550-NaM & 3.816 & 0.288 & 0.987 & 0.019 & 3.918 & 0.621 & 0.994 & 0.009 \\
\hline A-550-K & 3.336 & 0.204 & 0.976 & 0.029 & 3.433 & 0.432 & 0.993 & 0.009 \\
\hline C-600-NaM & 3.050 & 0.138 & 0.984 & 0.018 & 3.159 & 0.300 & 0.987 & 0.015 \\
\hline
\end{tabular}

3.3 Effect of operating conditions on dynamic adsorption performance

B-550-Fe, A-550-NaM and A-550-K were selected in the dynamic sorption column experiment for their high static adsorption capacities. The orthogonal experiment ( 3 factors with 3 levels, as mentioned in Section 2.4) results indicated that $\mathrm{NH}_{4}{ }^{+}-\mathrm{N}$ adsorption capacity of the biochar-fixed column was positively related with volume of treated slurry and sorption time (Table 4). ANOVA results showed height of fixed biochar was the main fact, which extremely significantly effecting on dynamic adsorption capacity, volume of treated slurry and sorption time $(p<0.01)$, in contrast with the fact of biogas slurry flow rate $(p>0.05)$. Types of packed modified biochar significantly influenced on dynamic adsorption capacity, volume of treated slurry and sorption time $(p<0.05)$. Range analysis method was used to select the optimal sorption process. Based on the results, as showed in Table 5, treatment of $\mathrm{A}_{2} \mathrm{~B}_{3} \mathrm{C}_{3}$ had the highest dynamic adsorption capacity, $A_{2} B_{2} C_{2}$ had the maximum throughput of biogas slurry, and $A_{2} B_{1} C_{1}$ had the shortest period of sorption time.

Table 4 Orthogonal test results of $\mathrm{NH}_{4}{ }^{+}-\mathrm{N}$ adsorption performance

\begin{tabular}{|c|c|c|c|c|c|c|c|}
\hline Treats & Name & $\begin{array}{l}\text { Flow } / L \cdot h^{-1} \\
\text { (A) }\end{array}$ & $\begin{array}{l}\text { Height } / \mathrm{cm} \\
\text { (B) }\end{array}$ & Biochars (C) & $\underset{/ \mathrm{mg} \cdot \mathrm{g}^{-1}}{\mathrm{NH}_{4}{ }^{+}-\mathrm{N} \text { adsorption capacity } Q}$ & $\begin{array}{l}\text { Volume of treated slurry } \\
/ \mathrm{L}\end{array}$ & $\begin{array}{l}\text { Sorption time } \\
/ / \mathrm{min}\end{array}$ \\
\hline $\mathrm{T} 1$ & $\mathrm{~A}_{1} \mathrm{~B}_{1} \mathrm{C}_{1}$ & 3 & 30 & B-550-Fe & 4.293 & 2.8 & 60 \\
\hline $\mathrm{T} 2$ & $\mathrm{~A}_{1} \mathrm{~B}_{2} \mathrm{C}_{2}$ & 3 & 50 & A-550-K & 5.861 & 6.5 & 231 \\
\hline $\mathrm{T} 3$ & $\mathrm{~A}_{1} \mathrm{~B}_{3} \mathrm{C}_{3}$ & 3 & 70 & A-550-NaM & 12.146 & 10 & 326 \\
\hline $\mathrm{T} 4$ & $\mathrm{~A}_{2} \mathrm{~B}_{1} \mathrm{C}_{3}$ & 5 & 30 & A-550-NaM & 8.011 & 5 & 169 \\
\hline T5 & $\mathrm{A}_{2} \mathrm{~B}_{2} \mathrm{C}_{1}$ & 5 & 50 & B-550-Fe & 6.889 & 6.5 & 106 \\
\hline $\mathrm{T} 6$ & $\mathrm{~A}_{2} \mathrm{~B}_{3} \mathrm{C}_{2}$ & 5 & 70 & A-550-K & 10.238 & 9 & 303 \\
\hline $\mathrm{T} 7$ & $\mathrm{~A}_{3} \mathrm{~B}_{1} \mathrm{C}_{2}$ & 7 & 30 & A-550-K & 6.023 & 4.5 & 149 \\
\hline $\mathrm{T} 8$ & $\mathrm{~A}_{3} \mathrm{~B}_{2} \mathrm{C}_{3}$ & 7 & 50 & A-550-NaM & 7.246 & 7.2 & 275 \\
\hline T9 & $\mathrm{A}_{3} \mathrm{~B}_{3} \mathrm{C}_{1}$ & 7 & 70 & $\mathrm{~B}-550-\mathrm{Fe}$ & 9.537 & 7.5 & 169 \\
\hline
\end{tabular}

Table 5 Extremum difference analysis results

\begin{tabular}{ccccc}
\hline Index & $K$ & $\mathrm{~A}$ & $\mathrm{~B}$ & $\mathrm{C}$ \\
\hline \multirow{2}{*}{$\begin{array}{c}\mathrm{NH}_{4}{ }^{+}-\mathrm{N} \\
\text { adsorption }\end{array}$} & $K_{2}$ & 22.301 & 18.327 & 20.720 \\
capacity & $K_{3}$ & 22.806 & 31.922 & 27.403 \\
& Range & 2.838 & 13.595 & 6.684 \\
& Optimal decision & & $\mathrm{B}_{3} \mathrm{C}_{3} \mathrm{~A}_{2}$ & \\
\hline \multirow{3}{*}{ Volume of } & $K_{1}$ & 19.3 & 12.3 & 16.8 \\
treated slurry & $K_{2}$ & 20.5 & 26.5 & 22.2 \\
& $K_{3}$ & 19.2 & 20.2 & 20.0 \\
& $R$ & 1.3 & 14.2 & 5.4 \\
& Optimal decision & & $\mathrm{B}_{2} \mathrm{C}_{2} \mathrm{~A}_{2}$ & \\
\hline \multirow{2}{*}{ Sorption time } & $K_{1}$ & 617.0 & 378.0 & 334.5 \\
& $K_{2}$ & 578.0 & 612.0 & 683.0 \\
& $K_{3}$ & 592.5 & 797.5 & 770.0 \\
& $R$ & 39.0 & 419.5 & 435.5 \\
\hline
\end{tabular}

\subsection{Dynamic adsorption performance of optimized process}

In order to select an optimal process to capture $\mathrm{NH}_{4}{ }^{+}-\mathrm{N}$ in biogas slurry using three-stage dynamic adsorption method, the study hypothesized that the $1^{\text {st }}$ sorption column should has short sorption time so that slurry could flow into the following column as quick as possible to prevent blocking and to enhance handling ability. The $3^{\text {rd }}$ sorption column should have better dynamic adsorption capacity, and function of the $2^{\text {nd }}$ sorption column should between the function of $1^{\text {st }}$ and the $2^{\text {nd }}$ sorption column.
Based on the hypothesis and the analysis in Section 3.3, $\mathrm{A}_{2} \mathrm{~B}_{1} \mathrm{C}_{1}, \mathrm{~A}_{2} \mathrm{~B}_{2} \mathrm{C}_{2}$ and $\mathrm{A}_{2} \mathrm{~B}_{3} \mathrm{C}_{3}$ were arranged in the $1^{\text {st }}, 2^{\text {nd }}$ and $3^{\text {rd }}$ sorption column device (Figure 1), respectively. Dynamic sorption capacity of each column increases gradually with the increasing of injected slurry volume, and eventually reached equilibrium (Figure 7). The equilibrium $\mathrm{NH}_{4}^{+}-\mathrm{N}$ adsorption capacities of $\mathrm{A}_{2} \mathrm{~B}_{1} \mathrm{C}_{1}, \mathrm{~A}_{2} \mathrm{~B}_{2} \mathrm{C}_{2}$ and $\mathrm{A}_{2} \mathrm{~B}_{3} \mathrm{C}_{3}$ were $7.57 \mathrm{mg} / \mathrm{g}$, $11.55 \mathrm{mg} / \mathrm{g}$ and $14.23 \mathrm{mg} / \mathrm{g}$, with the running time of $189 \mathrm{~min}$, $424 \mathrm{~min}$ and $584 \mathrm{~min}$, respectively. The maximum $\mathrm{NH}_{4}{ }^{+}-\mathrm{N}$ adsorption rate of the three-stage dynamic adsorption device could reach to $85.60 \%$.

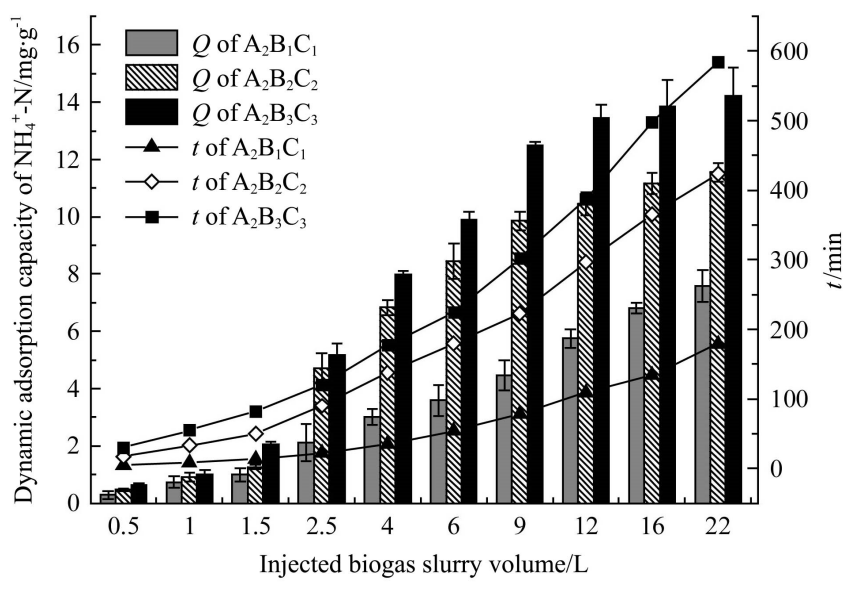

Figure 7 Adsorption effect of the optimized process on $\mathrm{NH}_{4}{ }^{+} \mathrm{N}$ 
The breakthrough curves of $\mathrm{NH}_{4}{ }^{+} \mathrm{N}$ adsorption of each column were shown in Figure 8. If taking the point $\left(C_{e}=0.5 C_{0}\right)$ as the penetration point, the penetration time of $\mathrm{A}_{2} \mathrm{~B}_{1} \mathrm{C}_{1}, \mathrm{~A}_{2} \mathrm{~B}_{2} \mathrm{C}_{2}$ and $\mathrm{A}_{2} \mathrm{~B}_{3} \mathrm{C}_{3}$ were $30 \mathrm{~min}, 90 \mathrm{~min}$ and $125 \mathrm{~min}$, respectively. If taking the point $\left(C_{e}=0.8 C_{0}\right)$ as the penetration point, the adsorption saturation time of $\mathrm{A}_{2} \mathrm{~B}_{1} \mathrm{C}_{1}, \mathrm{~A}_{2} \mathrm{~B}_{2} \mathrm{C}_{2}$ and $\mathrm{A}_{2} \mathrm{~B}_{3} \mathrm{C}_{3}$ were $190 \mathrm{~min}$, $350 \mathrm{~min}$ and $420 \mathrm{~min}$, respectively. The penetration time of the three-stage dynamic adsorption process were 6.67 times, 2.22 times and 1.6 times than the time of $\mathrm{A}_{2} \mathrm{~B}_{1} \mathrm{C}_{1}, \mathrm{~A}_{2} \mathrm{~B}_{2} \mathrm{C}_{2}$ and $\mathrm{A}_{2} \mathrm{~B}_{3} \mathrm{C}_{3}$ single-stage adsorption processes.

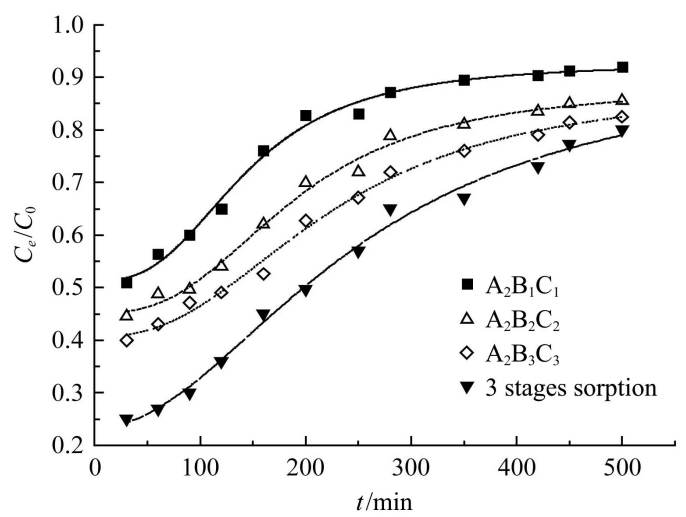

Figure 8 Breakthrough curves of $\mathrm{NH}_{4}^{+}-\mathrm{N}$ adsorption

\section{Conclusions}

This study investigated the physicochemical properties of modified biochars and dynamic sorption capacity of ammonium in a three-stage column packed with modified biochars from anaerobically digested slurry. Based on the results the following conclusions can be drawn:

1) The modified biochars with higher $\mathrm{NH}_{4}{ }^{+}-\mathrm{N}$ adsorption capacity were A-550-NaM $(8.51 \mathrm{mg} / \mathrm{g}), \mathrm{B}-550-\mathrm{Fe}(8.09 \mathrm{mg} / \mathrm{g})$, A-550-K $(7.58 \mathrm{mg} / \mathrm{g})$ and C-600-NaM $(7.60 \mathrm{mg} / \mathrm{g})$;

2) All sorption processes followed pseudo-second-order kinetics equation, implying that chemical reactions might have occurred during the $\mathrm{NH}_{4}{ }^{+}-\mathrm{N}$ sorption process, and the maximum $\mathrm{NH}_{4}{ }^{+}-\mathrm{N}$ removal rates of B-550-Fe, A-550-NaM, A-550-K and $\mathrm{C}-600-\mathrm{NaM}$ were $66.64 \%, 57.50 \%, 52.39 \%$ and $45.20 \%$, respectively;

3) Deeper packed biochar and applying lower flow rates could be benefit to increase $\mathrm{NH}_{4}{ }^{+}-\mathrm{N}$ adsorption;

4) The best adsorption process was selected in the three-stage adsorption process, and the maximum $\mathrm{NH}_{4}{ }^{+}-\mathrm{N}$ removal rate in the slurry could reach $85.60 \%$.

\section{Acknowledgements}

The present study was supported by the project of Indigenous Research and Development Program of AAPE (2018ZZYF0101) and Public Welfare Industry (Agriculture) Special Scientific Research (201503135).

\section{[References]}

[1] Chen L, Zhao L, Ren C, Wang F. The progress and prospects of rural biogas production in China. Energy Policy, 2012; 51: 58-63.

[2] Guo Y J, Tang H, Li G D, Xie D T. Effects of cow dung biochar amendment on adsorption and leaching of nutrient from an acid yellow soil irrigated with biogas slurry. Water Air Soil Pollution, 2014; 225: 1820

[3] Huang H, Zhang P, Zhang Z, Liu J, Xiao J, Gao F. Simultaneous removal of ammonia nitrogen and recovery of phosphate from swine wastewater by struvite electrochemical precipitation and recycling technology. Journal of cleaner production, 2016; 127: 302-310.

[4] FAO. Livestock's long shadow-environmental issues and options. Rome: FAO; 2006; 377p.

[5] Cao R K, Chen H, Zhao Y Z. Resource utilization of biogas slurry. China Biogas, 2015; 33(02): 42-50.(in Chinese)

[6] Ma Y R, Ding J T, Zhao L X, Meng H B, Shen Y J, Cheng H S, et al. Advances in recycling and reuse of nitrogen from biogas slurry. Environmental pollution and Prevention, 2018; 40(3): 339-344.

[7] Ganrot Z, Dave G, Nilsson E. Recovery of N and P from human urine by freezing, struvite precipitation and adsorption to zeolite and active carbon. Bioresource Technology, 2007; 98(16): 3112-3121.

[8] Turker M, Celen I. Removal of ammonia as struvite from anaerobic digester effluents and recycling of magnesium and phosphate. Bioresource Technology, 2007; 98(8): 1529-1534.

[9] Song Y H, Qiu G L, Yuan P, Cui X Y, Peng J F, Zeng P, et al. Nutrients removal and recovery from anaerobically digested swine wastewater by struvite crystallization without chemical additions. Journal of Hazardous Materials, 2011; 190(1-3): 140-149.

[10] Holmes J M, Beebe R A. An example of desorption hysteresis at low relative pressures on a non-porous adsorbent: ammonia on graphitized carbon black. Journal of Chemical Physics, 1957; 61(12): 1684-1686.

[11] Kurt A S, Jeff M N, Rodney T V. Biochar's role as an alternative N-fertilizer: Ammonia capture. Plant Soil, 2012; 350: 35-42.

[12] Sizmur T, Fresno T, Akgül G, Frost H, Jiménez E M. Biochar modification to enhance sorption of inorganics from water. Bioresource Technology, 2017; 246: 34-47.

[13] Mosa A, El-Ghamry A, Tolba M. Functionalized biochar derived from heavy metal rich feedstock: Phosphate recovery and reusing the exhausted biochar as an enriched soil amendment. Chemosphere, 2018; 198 351-363.

[14] Ahmedna M, Johns M M, Clarke S J, Marshall W E, Rao R M. Potential of agricultural byproduct-based activated carbons for use in raw sugar decolorization. Journal of the Science of Food and Agriculture, 1997; 75: 117-124.

[15] Glaser B, Lehmann J, Zech W. Ameliorating physical and chemical properties of highly weathered soils in the tropics with charcoal-a review. Biology and Fertility of Soils, 2002; 35(4): 219-230.

[16] Rajapaksha A U, Chen S S, Tsang D C W, Zhang M, Meththik V, Sanchit $\mathrm{M}$, et al. Engineered/designer biochar for contaminant removal/ immobilization from soil and water: Potential and implication of biochar modification. Chemosphere, 2016; 148:276-291.

[17] Shaaban M, van Zwieten L, Bashir S. A concise review of biochar application to agricultural soils to improve soil conditions and fight pollution. Journal of Environmental Management, 2018; 228: 429-440.

[18] Liu Y, Zhu Z Q, He X S, Yang C, Qiong D Y, Huang Y D, et al Mechanisms of rice straw biochar effects on phosphorus sorption characteristics of acid upland red soils. Chemosphere, 2018; 207: 267-277.

[19] Yang J, Hao L, Zhang D, Wu M, Pan B. Limited role of biochars in nitrogen fixation through nitrate adsorption. Science of the Total Environment, 2017; 592 (15): 758-765.

[20] Hale S E, Alling V, Martinsen V, Mulder J, Breedveld G D, Cornelissen G The sorption and desorption of phosphate-P, ammonium-N and nitrate-N in cacao shell and corn cob biochars. Chemosphere, 2013; 91(11): 1612-1619.

[21] Kizito S, Wu S B, Kipkemoi K W, Lei M, Lu Q, Bah H, et al. Evaluation of slow pyrolyzed wood and rice husks biochar for adsorption of ammonium nitrogen from piggery manure anaerobic digestate slurry. Science of the Total Environment, 2015; 505: 102-112.

[22] Liu N, Sun Z, Wu Z C, Zhan X, Zhang K, Zhao E, et al. Adsorption characteristics of ammonium nitrogen by biochar from diverse origins in water. Advances in Materials Research, 2013; 664: 305-312.

[23] Mizuta K, Matsumoto T, Hatate Y, Nishihara K, Nakanishi T. Removal of nitratenitrogen from drinking water using bamboo powder biochar. Bioresource Technology, 2004; 95(3): 255-257.

[24] Sarkhot D V, Ghezzehei T A, Berhe A A. Effectiveness of biochar for sorption of ammonium and phosphate from dairy effluent. Journal of Environmental Quality, 2013; 42(5): 1545-1554.

[25] Cui X Q, Hao H L, Zhang C K, He Z L, Yang X. Capacity and 
mechanisms of ammonium and cadmium sorption on different wetland-plant derived biochars. Science of the Total Environment, 2016; 539: 566-575.

[26] Chen B L, Zhou D D, Zhu L Z. Transitional adsorption and partition of nonpolar and polar aromatic contaminants by biochars of pine needles with different pyrolytic temperatures. Environmental Science \& Technology, 2008; 42: 5137-5143.

[27] Wang Z, Liu G, Zheng H, Li F, Ngo H H, Guo W, et al. Investigating the mechanisms of biochar's removal of lead from solution. Bioresource Technology, 2015; 177: 308-317. 